\title{
Agoniste en reseptore verantwoordelik vir die aktivering van bloedplaatjies: 'n kort oorsig
}

\author{
A.W. van Rijswijk* en A.E. du Toit \\ Departement Mens- en Dierfisiologie, Universiteit van Stellenbosch, Stellenbosch 7600 \\ Ontvang 14 Mei 1992; aanvaar 18 Augustus 1992
}

\section{UITTREKSEL}

Daar is min terreine van die fisiologie wat gedurende die laaste dekade so deeglik ondersoek is as die funksies van bloedplaatjies. Hierdie belangstelling is deels toe te skryf aan die toenemende bewustheid van die belangrike rol van bloedplaatjies in die liggaam. Hulle speel nie net 'n rol in hemostase nie, maar ook in ander fisiologiese prosesse soos fagositose, inflammasie, immunologiese reaksies en interaksie met tumorselle. Plaatjie-aktivering word deur spesifieke prosesse gereguleer, maardie meganisme waardeur dit geskied, is in baie gevalle nog onbekend. Aktivering van plaatjies word egter deur reseptorbinding geïnisieer, wat op sy beurt deur ekstrasellulêre seine beïnvloed word. Hierdie seine of stimuli kan na binding met die reseptor, antagonisties of agonisties wees. Die sekresie en aggregasie word sodoende negatief of positief beïnloed deurdat die stimulus in komplekse biologiese reaksies omgesit word. Hierdie oorsig dek nie die hele terrein van plaatjienavorsing nie en konsentreer slegs op 'n paar agoniste en meganismes betrokke gedurende die aktiveringsproses.

\begin{abstract}
Agonists and receptors responsible for the activation of blood platelets: a brief review

Few fields of physiology have been so intensely studied in the past decade as the function of platelets. This interest is partly due to the increasing realization of the important role of platelets in the body, not only during hemostasis but in other physiological processes such as phagocytosis, inflammation, immunological reactions and interaction with tumor cells. Platelet activation is regulated by specific mechanisms, many of which are unknown. However, activation is initiated by receptor binding, which is influenced by extracellular signals. These signals or stimuli could be antagonistic or agonistic and can therefore, after binding to the receptor, either inhibit or induce secretion and aggregation by transforming these signals into complex biological reactions. This review cannot cover the entire field of platelet research and therefore concentrates on only a few agonists and mechanisms involved in the activation process.
\end{abstract}

\section{INLEIDING}

Plaatjies speel nie net ' $n$ belangrike rol in hemostase nie, maar ook in ander fisiologiese prosesse soos fagositose, inflammatories en immunologiese reaksies en interaksie met tumorselle.

Plaatjies toon aldus 'n wye verskeidenheid van sellulêre reaksies. Plaatjies se spesifisiteit ten opsigte van hulle sellulêre organisasie en integriteit is dus noodsaaklik vir hulle doeltreffende funksionering. Hierdie organisering is veral afhanklik van die teenwoordigheid en toestand van sowel die plasmamebraan as intrasellulêre organelle. Die plasmamembraan speel veral ' $n$ belangrike rol in die binding van eksterne stimuli, die transduksie van seine tot binne-in die plaatjie en die uitvoering van die plaatjierespons. Plaatjies is toegerus met spesifieke plasmamembraanreseptore wat hierdie stimuli herken en daarop reageer. Oor die algemeen word plaatjies geaktiveer wanneer reseptorbesetting plaasvind. Die positiewe en negatiewe ekstrasellulêre seine word omgesit in komplekse biologiese reaksies deur middel van prosesse van seinresponskoppeling wat bewerkstellig word deur intrasellulêre tweede boodskappers - waarna die plaatjies dan 'n rol speel in verskeie biologiese reaksies. Aktivering van plaatjies as gevolg van die beskadiging van die bloed- vatwand het tot gevolg dat plaatjies prosesse van adhesie, vormverandering, sekresie en aggregasie ondergaan. Hierdie prosesse kan afsonderlik in vitro bestudeer word, maar gedurende hemostase in vivo is dit intakt.' Alhoewel plaatjiestimuli en plaatjiereaksies verskillend is, blyk dit dat plaatjieaktivering deur spesifieke meganismes gereguleer word. Binding aan spesifieke reseptore op die plaatjie-oppervlak ${ }^{2}$ is kenmerkend van alle fisiologiese plaatjiestimuli (eksitatories en inhibitories). ${ }^{3}$

Plaatjie-aktivering word deur bepaalde meganismes gereguleer, maar word deur reseptorbesetting geïnisieer. Die sein wat vanaf die geaktiveerde reseptor ontstaan, word via Guanosien trifosfaat (GTP)-bindende proteiene oor die plasmamembraan gedra. ${ }^{4}$

Twee hoof seinoordragingsweë word in die meeste selstudies beskryf:

* Die vernaamste aktiveringsweg gebruik 'n kombinasie van tweede boodskappers afkomstig vanaf ensiemafhanklike hidrolise van inositol fosfolipase:inositol 1,4,5trifosfaat $\left(\mathrm{IP}_{3}\right)$ en $s n$-1,2-deasielgliserol (DG). ${ }^{5}$

* Die vernaamste inhibitoriese weg in plaatjies gebruik sAMP as tweede boodskapper. ${ }^{6}$ 
Die tweede boodskapper van albei weë word in die membraan opgewek deur aktivering van membraangeassosieerde seinwekkende ensieme (bv. fosfolipase C) deur reseptorafhanklike veranderings in 'n familie van GTP-bindende regulatoriese proteiene ( $G$-proteiene). In elke geval verander die geaktiveerde seinwekkende ensieme hoogs gefosforileerde voorlopermolekule na intrasellulêre tweede boodskappers:

* Fosfolipase C kloof die membraanfosfolipied fosfatidielinositol 4,5-bisfosfaat (PIP ${ }_{2}$ ) in $\mathrm{IP}_{3}$ en $\mathrm{DG}^{7}$ terwyl

* adinielsiklase ATP omsit na sAMP. ${ }^{3}$

Hierdie tweede boodskappers wat gevorm word, oefen hul intrasellulêre aksies uit deur konformasieveranderings (direk of indirek) in teikenproteïene te induseer deur die aktivering van proteïenkinases:

* $\mathrm{IP}_{3}$ stel kalsium $\left(\mathrm{Ca}^{2+}\right.$ ) vry wat aan kalmodulien bind en die aktivering van $\mathrm{Ca}^{2+} / \mathrm{kalmodulien-afhanklike}$ proteïenkinase tot gevolg het. ${ }^{8}$ DG veroorsaak die aktivering van proteïenkinase $\mathrm{C} .{ }^{9}$

* sAMP het die aktivering van sAMP-afhanklike proteienkinase tot gevolg.

Die aktiveringsproses word skematies in figuur 1 voorgestel.

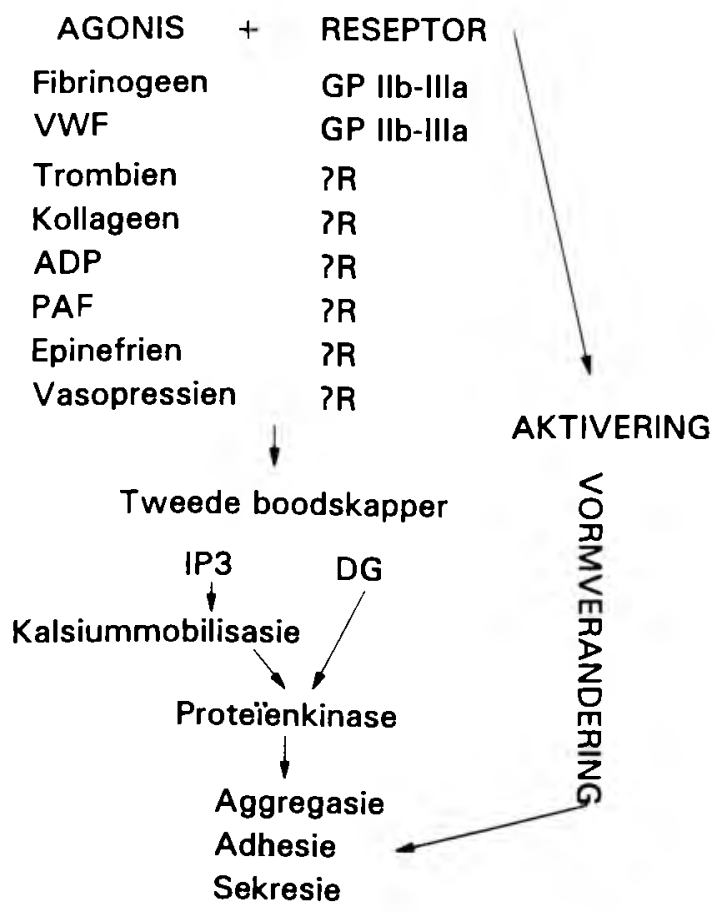

FIGUUR 1: 'n Skematiese voorstelling van gebeure wat lei tot aggregasie, adhesie en sekresie.

\section{PLAATJIES - AGONISTE EN RESEPTORE}

\section{Von Willebrand-faktor (vWF)}

Hierdie faktor speel 'n sentrale rol in die adhesie van plaatjies aan die subendoteel (primêre hemostase). ${ }^{10,11,12}$ Plaatjie-vWF ( $20 \%$ van die totale $\mathrm{VWF}$ in sirkulasie) is ' $n$ multimeriese glikoproteïen (440-20000 kDa.) primêr gelokaliseer in plaatjiegranules met'n klein hoeveelheid wat op die oppervlak van rustende plaatjies teenwoordig is. ${ }^{13} \mathrm{Na}$ trombien- en kollageenstimulasie neem die teenwoordigheid van vWF op die oppervlak drasties toe. ${ }^{14,15}$

Behalwe vir die teenwoordigheid van vWF in die plaatjies self, is dit ook in die bloed en subendoteel van bloedvate teenwoordig waar dit 'n belangrike bydrae tot plaatjieadhesie lewer." Von Willebrand-faktor word in die endoteelselle ${ }^{16}$ en megakariosiete ${ }^{17}$ gesintetiseer. Dit word vanuit die endoteelselle in die subendoteel en die sirkulasie vrygestel. ${ }^{18}$ In die plasma staan vWF as Faktor VIII-vWF bekend, maar hierdie niekovalente kompleks is egter in die plaatjie self afwesig. ${ }^{19}$

Die primêre reseptor vir die binding van $v W F$ aan geaktiveerde plaatjies is die glikoproteien $1 \mathrm{lb}-11 \mathrm{la}$ (GPIlb111 a)-kompleks..$^{20.12}$ Deur middel van fisiologiese stimuli soos ADP en trombien word die bindingsetels vir vWF ontbloot. ${ }^{20}$ Die blootstelling van die vWF-bindingsetel op die GP IIb-IIIa-kompleks is gedeeltelik afhanklik van ADP en plaatjietromboksaan $A_{2}\left(T_{x} A_{2}\right)^{22}$ en kan geheel en al deur plaatjie-sAMP-vlakke onderdruk word ${ }^{21}$

Die interaksie van $v W F$ met plaatjies is essensieel vir hul adhesie aan die subendoteel. vWF vereis spesifiek $\mathrm{Ca}^{2+}$ vir sy optimale biologiese aktiwiteit om plaatjie-adhesie te bewerkstellig, terwyl plaatjieverspreiding op die subendoteel daarna of $\mathrm{Ca}^{2+}$ of $\mathrm{Mg}^{2+}$ nodig het. ${ }^{23}$

\section{Kollageen}

Monomeriese kollageen (tropokollageen, $300 \mathrm{kDa}$.) is ' $\mathrm{n}$ drievoudige spoel wat uit een $\alpha$-en twee $\beta$-kettings bestaan. Mikrofibrillêre kollageen is ' $n$ hoogs geordende struktuur van verskeie molekulêre massas wat wissel vanaf $106 \mathrm{kDa}$ tot $109 \mathrm{kDa} .{ }^{18}$ Plaatjie-adhesie aan monomeriese en fibrillêre kollageen is afhanklik van divalente katione en word deur $\mathrm{Mg}^{2+}$ ondersteun, terwyl fisiologiese konsentrasies $\mathrm{Ca}^{2+}$ inhibitories van aard is. ${ }^{25}$

Kollageen toon interaksie met baie uiteenlopende proteiene o.a. fibronektien, ${ }^{26}$ fibrinogeen ${ }^{27}$ en Faktor VIIIvWF. ${ }^{28.29 .30}$ As gevolg hiervan is 'n verskeidenheid reseptore vir kollageen voorgestel bv. Faktor XIII; ${ }^{27}$ VLA-2; ${ }^{31}$ glikoproteïen Ilb; ${ }^{32}$ fibronektien; ${ }^{33}$ in 61 kDa.-membraanglikoproteïen ${ }^{34}$; 'n 65 kDa.-membraan-glikoproteien ${ }^{35}$ en komplement Cls. ${ }^{36}$ Sekere navorsers ${ }^{37.25}$ sluit egter die moontlike rol van fibronektien en glukosieltransferase as kollageenreseptore uit. Verder is aangetoon dat fibronektien plaatjie-aggregasie deur kollageen kan inhibeer. ${ }^{25}$ Ander navorsers $^{10}$ beweer egter dat fibronektien wel 'n rol in plaatjiekollageeninteraksie speel. Daarbenewens stel hulle 'n aparte bindingsetel vir Faktor VIII-vWF en fibronektien op kollageen voor. Die meganisme van plaatjiebinding aan kollageen is nog onbekend, maar daar word beweer ${ }^{10}$ dat sowel Faktor VIII-vWF as fibronektien betrokke is by plaatjieinteraksie tussen monometriese kollageen tipes I en III, maar nie nodig is vir optimale plaatjie-interaksie met fibrillêre kollageen I en III nie. Verskeie pogings is aangewend om die reseptor op die plasmamembraan van plaatjies te identifiseer. Daar is voorgeste ${ }^{27}$ dat dit kollageenbindende proteïen is en daar word gespekuleer dat hierdie proteien moontlik Faktor XIlI kan wees, aangesien Faktor XIII op die plaatjieoppervlak voorkom en dus as reseptor kan optree. Takada en Hemler $(1989)^{31}$ het weer VLA-2, 'n $\alpha / \beta$-subeenheid seloppervlakteheteromeer, as reseptor vir kollageen voorgestel. Hulle substansieer dit deur aan te toon dat VLA-2 identies is 
aan 'n 150,000/1 10,000 molekulêre massa plaatjie-proteïenkompleks wat deur monoklonale teenliggaampies herken word. Hierdie teenliggaampies blokkeer spesifiek menslike fibrosarkoma-selle en plaatjie-adhesie aan kollageen. Daarbenewens toon pasiënte met 'n tekort aan plaatjieproteïen Ia 'n gebrek aan respons met kollageen. ${ }^{31}$ Geeneen van die eksperimentele studies om die spesifieke kollageenreseptor te identifiseer, toon egter aan of die betrokke geisoleerde kollageenbindende membraanareas essensieel is vir kollageengeïnduseerde plaatjie-aktivering nie. ${ }^{18}$

\section{Trombien}

Trombien is 'n kragtige aktiveerder van plaatjie-adhesie, aggregasie en sekresie. ${ }^{38}$ Die binding van trombien aan plaatjies is ' $n$ vinnige proses wat ook omkeerbaar is. ${ }^{39}$ Indien mensplaatjies aan trombien blootgestel word, ondergaan die plaatjies 'n dramatiese morfologiese verandering deurdat dit vanaf diskus na sferiese vorm met verskeie filopodia verander. ${ }^{40}$ Die diskoïede plaatjie se vorm raak gerond en die granules wat in die middel saamklomp, versmelt met mekaar en met ander elemente van die oppervlak-kanalikulêre sisteem om groot vakuole te vorm. Hierdie proses veroorsaak dat fibrinogeen, $\beta$-TGen PF4, wat in die $\alpha$-granules gestoor word, na hul plasmamembrane geherdistribeer word deur middel van die vakuole wat met die oppervlakte verbind is. ${ }^{41}$ Hierdie morfologiese verandering is die gevolg van die polimerisasie van aktien na filamente ${ }^{4 l}$ en 'n verhoogde organisasie van aktienfilamente met ander sitoskelet-proteïene. ${ }^{40}$ Behalwe vir die morfologiese verandering het Michelson en Barnard $(1987)^{43}$ die volgende waarnemings met betrekking tot die trombiengeïnduseerde veranderings gemaak:

1. Die merkbare vermindering in binding van teenliggaampies gerig teen Glikoproteien Ib (GP Ib) op die plaatjieoppervlakte, is nie beperk tot teenliggaampies gerig teen die vWF-bindingsetel nie.

2. Daar is ' $n$ merkbare vermindering in plaatjieoppervlakbinding van ' $n$ teenliggaampie gerig teen GP IX sonder dat die 1:1 verhouding van plaatjieoppervlakbinding tot teenliggaampies gerig teen GP Ib en GP IX, beïnvloed word.

3. Veranderings in binding van teenliggaampies op die plaatjieoppervlakte is nie beperk tot 'n spesifieke subpopulasie van plaatjies nie.

4. Daar is geen geassosieerde vrystelling van glikokalisien vanaf die plaatjies nie.

5. Daar is geen geassosieerde vrystelling van die GP IIbIIIa-kompleks vanaf plaatjies nie.

Wanneer plaatjies deur trombien geaktiveer word, toon trombien interaksie met plaatjies op ten minste twee posisies:

(i) 'n Hormoonagtige binding aan GP Ib. ${ }^{44.45}$ Die binding van trombien aan intakte plaatjies is vinnig, volledig en omkeerbaar. Trombien toon interaksie met GP lb wat op sy beurt in staat is om interaksie met sitoskelet-proteïene te toon. Hierdie veranderings is essensieel vir die reaksie van plaatjies met die beskadigde bloedvatwand en ook met ander plaatjies.

ii) ' $n$ Proteolitiese afbraak van membraanglikoproteien $V^{46}$ en aggregien, 'n ADP-reseptor. ${ }^{47}$

Behalwe dat trombien interaksie met GP Ib toon, ${ }^{46,48}$ toon GP Ib op sy beurt weer interaksie met proteiene van die sitoskelet, veral aktienbindende proteiene ${ }^{49}$ en GP IX. ${ }^{50}$
Deur die hoë affiniteitstrombienreseptore te beset en die gevolglike ensiemaktiwiteit vind 'n verhoging van $\mathrm{Ca}^{2+}$ in die sitosol van plaatjies plaas en dit het die intrasellulêre aktivering van kalpaien ('n $\mathrm{Ca}^{2+}$-afhanklike protease) tot gevolg. ${ }^{47}$ Kalpaien kloof membraanproteïene en bevorder dissosiasie van membraanproteiene vanaf die sitoskelet. ${ }^{51}$ Trombiengeinduseerde plaatjiesameklomping gaan gepaard met splitsing van aggregien. ${ }^{52}$ Deur hierdie splitsing van aggregien word die fibrinogeenreseptore ontbloot en sodoende vind aggregasie plaas. Die proteolitiese funksie van trombien vind dus indirek deur aktivering van die intrasellulêre proteïen, kalpaien, plaas.

\section{Adenosiendifosfaat (ADP)}

Verskeie stimuli lei tot plaatjie-aggregasie, bv. ADP, trombien, epinefrien, prostaglandien-endoperoksiedes, kollageen en aragidonaat, ${ }^{53}$ maar dit is slegs ADP wat fibrinogeen as ko-faktor nodig het om aggregasie te bewerkstellig. ${ }^{54}$

Twee hoof effekte, wat oënskynlik onafhanklik en nieverwand is, kan onderskei word:

i) Die induksie van plaatjievormverandering, die blootstel-

ling van fibrienogeenreseptore en aggregasie.

ii) Die inhibisie van prostaglandien $\mathrm{E}_{1} \cdot{ }^{18}$

Sommige skrywers ${ }^{55}$ is van mening dat hierdie twee effekte van ADP deur twee afsonderlike reseptore bewerkstellig word. Inligting wat tot dusver ingewin is, pas goed in by ' $n$ model van ADP-binding aan twee verskillende setels, maar egter op een reseptor. Hierdie twee setels is onderskeidelik gekoppel aan adenilaatsiklase-inhibisie en vormverandering, aggregasie, en het dieselfde affiniteit vir ADP. ${ }^{18}$ Die aggregasie-effek van ADP word gemoduleer deur die membraanpotensiaal. ${ }^{56}$

Die regulering van die ADP-reseptor in plaatjies is van groot belang. Epinefrien verhoog byvoorbeeld die affiniteit van ADP vir die ADP-reseptor tienvoudig sonder om die aantal reseptore te beïnvloed. ${ }^{57}$

\section{Plaatjie-aktiveringsfaktor}

Plaatjie-aktiveringsfaktor (PAF) of 1-alkiel-2-asetiel-snglisero-3-fosfocholien is een van die effektiefste plaatjieagoniste wat bekend is. ${ }^{58}$ Alkiel-gliseriel-eter-fosfocholien (AGEPC), PAF-aseter en alkielasetiel-GPC word ook as sinonieme van PAF gebruik. ${ }^{59}$ PAF aktiveer menslike plaatjies by konsentrasies van $1^{-10} \mathrm{nM} .^{60}$

PAF word deur middel van spesifieke stimulasie deur neutrofiele, basofiele en makrofage gesekreteer. ${ }^{18}$ Spesiale omstandighede is egter nodig vir die binding van neutrofiele aan die endoteelselle om intersellulêre adhesie te reguleer. ${ }^{61}$ Wanneer endoteelselle deur trombien gestimuleer word, vind daar 'n tydelike akkumulasie van PAF plaas, 'n gedeelte waarvan op die plasmamembraan van die endoteelsel teenwoordig is. Dit veroorsaak dat die neutrofiele daaraan vaskleef. Sodoende veroorsaak PAF wat met die endoteelselmembraan geassosieer is, neutrofielbinding. Kompeterende antagoniste van die PAF-reseptor inhibeer hierdie binding. Dit inhibeer egter nie die binding aan endoteelselle wat deur tumor-nekrose-faktor- $\alpha$ veroorsaak word nie. Dit dui daarop dat PAF wat endogenies deur endoteelselle gesintetiseer word, as mediator vir neutrofieladhesie kan optree. ${ }^{61}$ Alhoewel PAF ook in lipiedekstrak van amnionvog 
van dames tydens kraam gevind is, kon dit nie in hierdie vloeistof voor die aanvang van kraam aangetoon word nie. ${ }^{62}$ As gevolg van die hidrofobiese geaardheid van PAF is dit moeilik om spesifieke reseptore vir PAF aan te toon. ${ }^{63}$ Daar is egter gedurende $1984^{64} \mathrm{n} 180 \mathrm{kDa}$.-proteien geïdentifiseer wat spesifiek aan PAF bind en in 1985 is 'n soortgelyke 160 kDa.-proteien geisoleer. ${ }^{65}$

Daar is ook gevind ${ }^{53}$ dat katione PAF-binding beinvloed deurdat die PAF-reseptor in 'n hoëaffiniteitstoestand geplaas word deur $\mathrm{Mg}^{2+}$ en in 'n laeaffiniteitstoestand in die teenwoordigheid van $\mathrm{Na}^{+}$. Kalsium aan die ander kant is nie nodig vir die binding aan plaatjies nie. ${ }^{53}$ Aan die ander kant word beweer ${ }^{6 t}$ dat PAF-binding aan spesifieke reseptore 8 tot 10 maal vermeerder in die teenwoordigheid van $\mathrm{Ca}^{2+}, \mathrm{Mg}^{2+}$ en $\mathrm{Mn}^{2+}$.

Daar word ook beweer dat tromboksaan $\mathrm{A}_{2}$ en ADP belangrike mediators in PAF-geïnduseerde fibrinogeenbinding is. PAF inisieer fibrinogeenbinding deur:

i) besetting van PAF-reseptore;

ii) aktivering van tweede boodskappers;

iii) blootstelling van fibrinogeenbindingsetels. ${ }^{53}$

PAF self is aangetoon as ' $n$ intrasellulêre modulator van selfunksie ${ }^{58}$ deurdat PAF adsorpsie met feitlik enige fosfolipieddubbellaag toon en as gevolg van 'n hidrofobiese karakter, daar deurbeweeg. Die direkte beweging tot in die sel kan egter die deelname van een of meer proteiene vereis wat interaksie bewerkstellig met spesifieke membrane en PAF sodoende beskerm teen asetielhidrolase wat in die sitosol teenwoordig is. ${ }^{63}$ Sodoende tree PAF op as 'n mediator van verskeie inflammatoriese, respiratoriese en kardiovaskulêre afwykings. ${ }^{58}$ Daarbenewens is aangetoon ${ }^{67}$ dat twee van die vier primêre katioonproteïene van die eosinofielgranule, nl. "major basic protein" (MBP) en eosinofielperoksidase (EPO), plaatjie-agoniste is en heelwaarskynlik 'n rol speel in die patogenese van verskeie siektes bv. asma. Die respons van plaatjies tot verskeie konsentrasies van PAF gedurende swangerskap, asook postpartum, is ook ondersoek. ${ }^{68}$ Daar is gevind dat die respons van plaatjies tot PAF óf afwesig, óf geweldig verminder was gedurende die 2230 ste week van swangerskap, maar in die postpartumperiode het dit na normaal teruggekeer. Hierdie verskynsel is verklaar deur die moontlikheid daar te stel dat die PAF-vlakke in die sirkulasie moontlik van die fetus afkomstig kan wees en sodoende die plaatjiereseptore desensitiseer, wat tot ' $n$ verminderde of afwesige respons van plaatjies vir PAF sou lei.

\section{Vasopressien}

Vasopressien word geproduseer deur die mediaaneminens van die hipotalamus. Dit word deur die neurohipofise in die sistemiese sirkulasie vrygestel en tree fisiologies as ' $n$ antidiuretiese hormoon op. ${ }^{69}$ Dit is 'n effektiewe plaatjiestimulus by konsentrasies van 1,0 nM en hoër soos verkry word tydens strestoestande, bv. 'n operasie en ernstige hipotensie as gevolg van bloedverlies. ${ }^{70}$ Gedurende normale toestande is die konsentrasie te laag om plaatjies te aktiveer.

$\mathrm{Mg}^{2+}$ en ander divalente ione speel ' $\mathrm{n}$ belangrike rol in die binding van vasopressien aan sy reseptor, maar ekstrasellulêre $\mathrm{Ca}^{2+}$ is egter nie essensieel vir vasopressien-geïnduseerde plaatjie-aktivering nie. ${ }^{71}$

\section{Epinefrien}

Katesjolamiene is belangrike agoniste vir plaatjie-aktivering. Epinefrien is agt keer meer effektief as norepinefrien. Die konsentrasies van katesjolamiene word ook verhoog gedurende strestoestande (of rook) en kan 'n patofisiologiese verskynsel in plaatjie-aktivering teweeg bring. ${ }^{22}$ Benewens die feit dat epinefrien plaatjie-aggregasie induseer, ${ }^{73}$ inhibeer dit ook adenilaatsiklase. ${ }^{74}$

Beide hierdie prosesse word bewerkstellig deur die aktivering van $\alpha 2$-adrenergiese reseptore. ${ }^{75}$ Die aggregasieresponse is ' $n$ direkte effek van epinefrien en is onafhanklik van die ekstrasellulêre teenwoordigheid van ADP of ander plaatjiestimuli. ${ }^{76}$ Die inhibisie van adenilaatsiklase is egter GTP-afhanklik. ${ }^{77}$

\section{Fibrinogeen}

Dit is reeds gedurende 1971 bewys $^{78}$ dat die interaksie van fibrinogeen met plaatjies noodsaaklik is vir aggregasie om plaas te vind. Fibrinogeen bind aan spesifieke reseptore op plaatjies en hierdie setels word nie net deur ADP geïnduseer nie, ${ }^{79}$ maar is ook normaalweg slegs funksioneel na ADPstimulasie. ${ }^{80}$ Verskeie agoniste induseer die blootstelling van fibrinogeenreseptore op plaatjies $\mathrm{nl}$. ADP, epinefrien, kollageen, arachidonaat en vWF. $^{81}$ Gedurende 1990 het navorsers ${ }^{82}$ egter aangetoon dat UV-B-strale ook plaatjieaggregasie veroorsaak deur die ontbloting van fibrinogeensetels via ' $n$ intersellulêre meganisme. Die meganisme van regulering van die fibrinogeen-reseptor-blootstelling wek egter nog groot belangstelling.

Die membraanglikoproteien GP IIb-IIIa, wat 'n $\mathrm{Ca}^{2+}$ afhanklike heterodimeer is en aan adhesieproteiene met 'n gemeenskaplik herkenbare aminosuur volgorde, Arg-GlyAsp (RGD) bind, is die plaatjiefibrinogeen-reseptor. ${ }^{83}$ Hierdie reseptor bind egter aan twee ander RGD-bevattende proteiene, fibronektien ${ }^{84}$ en $v W F .{ }^{85}$ Daar is gevind dat die 27 residu $\mathrm{COOH}$-terminale fragment van fibrinogeen se $\alpha$-ketting die binding van fibrinogeen aan plaatjies inhibeer ${ }^{86}$ Dit is bevestig deur onlangse studies ${ }^{87}$ waarin twee stelle sintetiese peptiedes, RGDX-peptiedes (waar X een of verskeie aanvaarbare aminosure kan wees) en peptiedes wat met die $\mathrm{COOH}$-terminaal van die fibrinogeen $\alpha$-ketting ooreenstem, vergelyk is ten opsigte van hul struktuurfunksionele verwantskap, en wat aangetoon het dat:

(a) beide RGDX en $\alpha$-kettingpeptiede die binding van fibrinogeen aan plaatjies en endoteelselle inhibeer;

(b) die residu van elke peptied 'n merkbare invloed by die $\mathrm{COOH}$ - en $\mathrm{NH}_{2}$-terminale het;

(c) RGDX en $\alpha$-peptiede verskillende effekte op plaatjies en endoteelselle het met betrekking tot die strukturele benodigdhede.

Aan die ander kant stimuleer lae temperature chimotripsien en elastase plaatjies om sy fibrinogeenreseptore te ontbloot. ${ }^{18}$ Die meganisme waardeur dit geskied, is egter nog onbekend.

\section{Gevolgtrekking}

Die aktivering van plaatjies is 'n komplekse meganisme waarby baie verskillende stimuli en ingewikkelde oordragingsmeganismes betrokke is. Die meeste bindingsetels vir die stimuli is bekend, maar sekere reseptore op die plaatjiemembraan is nog nie geïdentifiseer nie, ten spyte van die feit dat die meganismes van plaatjie-aktivering die afgelope 30 
jaar suksesvol nagevors is.

Die feit dat plaatjies aktien- en miosienfilamente besit wat kontraksie tydens vormverandering en die vrystellingsreaksie moontlik maak, is maar een van die bewyse dat plaatjies baie meer kompleks en interessant is as net nog 'n tipe bloedsel wat belangrik tydens hemostase is.

\section{I.ITERATUURVERWYSINGS}

1. Akkerman, J.W.N. \& Holmsen, H. (1981). Interrelationships among platelet responses: Studies on the burst in proton liberation, lactate production, and oxygen uptake during platelet aggregation and $\mathrm{Ca}^{2+}$ secretion, Blood, 57, 956

2. Jennings, L.K., Fox, J.E.B., Edwards, H.H. \& Phillips, D.R. (1981). Changes in the cytoskeletal structure of human platelets following thrombin activation, J. Biol. Chem., 56, 6927.

3. Kroll, M.H. \& Schafer, A.I. (1989). Biochemical mechanisms of platelet activation, Blood, 74, 1181.

4. Fisher, T.H., Gatling, M.N., Lacal, J. \& White, G.C. (1990). raplB, a cAMP-dependent protein kinase substrate, associates with platelet cytoskeleton, J. Biol. Chem., 265, 19405.

5. Kroll, M.H., Zavoico, G.B. \& Schafer, A.I. (1989). Second messenger function of phosphatidic acid in platelet activation, J. Cell Physiol., 139, 558.

6. Lerea, K.M., Glomset, J.A. \& Krebs, E.G. (1987). Agents that elevate cAMP levels in platelets decrease thrombin binding, J. Biol. Chem., $262,282$.

7. Hartwig, J.H., Kirstem, A.C., Hopcia, K.L. \& Kwiatkowski, D.J. (1989). Association of profilin with filament-free regions of human leucocytes and platelet membranes and reversible membrane binding during platelet activation, J. Cell Biol., 109, 1571.

8. Adunyah, S.E. \& Dean, W.L. (1987). Regulation of human platelet membrane $\mathrm{Ca}^{2+}$ transport by cAMP- and calmodulin-dependent phosphorylation, Biochim. Biophys. Acta, 930, 401.

9. Phillips, D.R. \& Baughan, A.K. (1983). Fibrinogen binding to human platelet plasma membranes, J. Biol. Chem., 258, 10240.

10. Houdijk, W.P.M., Sakariassen, K.S., Nievelstein, P.F.E.M. \& Sixma, J.J. (1984). Role of factor VIII/von Willebrand factor and fibronectin in the interaction of platelets in flowing blood with monomeric and fibrillar human collagen types I and III, J. Clin. Invest., 75, 531.

11.Stel, H.V., Sakariassen, K.S., De Groot, P.G., Van Mourik, J.A. \& Sixma, J.J. (1985). Von Willebrand Factor in the vessel wall mediates platelet adherence, Blood, 65, 85 .

12. Handgan, R.R., Hindriks, G., Taylor, R.G., Sixma, J.J. \& De Groot, P.G. (1990). Glycoprotein Ib, Von Willebrand factor, and glycoprotein IIbIIIa are all involved in platelet adhesion to fibrin in flowing whole blood, Blood, 76, 345.

13. Wencel-Drake, J.D., Painter, R.B.,Zimmerman, T.S. \& Ginsberg, M.H. (1985). Ultrastructural localization of human platelet thrombospondin, fibrinogen, fibronectin and von Willebrand factor in frozen thin sections, Blood, 65, 929.

14. Fernandez, M.F.L., Ginsberg, G.M.H., Ruggeri, Z.M., Batlle, F.J. \& Zimmerman, T.S. (1985). Multimeric structure of platelet factor VIIl/ von Willebrand factor: The presence of longer multimers and their reassociation with thrombin-stimulated platelets, Blood, 60, 1132.

15. George, J. \& Onofre, A.R. (1985). Human platelet surface binding of endogenous secreted factor VIII/von Willebrand factor and platelet factor-4, Blood, 59, 194.

16. Hoyer, L.W., Delossantos, R.P. \& Hoyer, J.R. (1973). Antihemophillic factor antigen, localization in endothelial cells by immunoflurescent microscopy, J. Clin. Invest., 52, 2737.

17. Nachman, R.L., Levine, R. \& Jaffe, E.A. (1977). Synthesis of factor VIII antigen by cultured guinea pig megakaryocytes, J. Clin. Invest., 60 , 914

18. Siess, W. (1989). Molecular mechanisms of platelet activation, Physiol. Rev., 69, 58.

19. Meucci, P., Peake, I.R. \& Bloom, A.L. (1978). Factor VIII-related activities in normal, haemophilic and von Willebrand's disease platelet fractions, Throm. Haemostasis, 40, 288.

20. Parker, R.I. \& Gralnick, H.R. (1986). Identification of platelet glycoprotein Ilb-IIIa as the major binding site for released platelet von Willebrand factor, Blood, 68, 732 .

21. Fujimoto, T., Ohara, S. \& Hawiger, J. (1982). Thrombin-induced exposure and prostacyclin inhibition of the receptor for factor VIII/von Willebrand factor on human platelets, J. Clin. Invest., 69, 1212.
22. Di Minno, G., Shapiro, S.S., Catalano, P.M., De Marco, L. \& Murphy, S. (1983). The role of ADP secretion and thromboxane synthesis in factor VIII binding to platelets, Blood, $62,186$.

23. Sakariassen, K.S., Ottenhof-Rovers, M. \& Sixma, J.J. (1984). Factor VIII-von Willebrand factor requires calcium for facilitation of platelet adherence, Blood, 63, 996.

24. Peterson, D.M., Stathopculos, N.A., Glorgio, T.D., Hellums, J.D. \& Moake, J.L. (1987). Shear-induced platelet aggregation requires von Willebrand factor and platelet membrane glycoprotein Ib and IIb-IIIa, Blood, 69, 625 .

25. Santoro, S.A. (1986). Identification of a 160000 dalton platelet membrane protein that mediates the initial divalent cation-dependent adhesion of platelets to collagen, Cell, 46, 913.

26. Dessau, W., Adelman, B.C., Timpl, R. \& Martin, G.R. (1978) Identification of sites in collagen $\alpha$-chain that bind serum anti-gelatin factor, Biochem. J., 165, 55

27. Saito, Y., Imanda, T., Takagi, J., Kikichi, T. \& Inadia, Y. (1986) Platelet factor XIII. The collagen receptor?, J. Biol. Chem., 261, 1355.

28. Kessler, C.M., Floyd, C.M., Rick, M.E., Krizek, D.M., Lee, S.L. \& Gralnick,H.R. (1984). Collagen-factor VIII/von Willebrand factor protein interaction, Blood, 63, 1291

29. Bockenstedt, P., Greenberg, J.M. \& Handin, R.I. (1986). Structural basis of von Willebrand factor binding to platelet glycoprotein Ib and collagen. Effects of disulphide reduction and limited proteolysis of polymeric von Willebrand factor, Blood, 77, 743.

30. Girma, J-P., Kalafatis, M., Pietu, G., Lavergne, J-M., Chopek, M.W. Edgington, T.S. \& Meyer, D. (1986). Mapping of distinct von Willebrand factor domains interacting with platelet GPIb and GPIIb-IIIa and with collagen using monoclonal antibodies. Blood, 67, 1356

31. Takada, Y. \& Hemler, M.E. (1989). The primary structure of VLA-2/ collagen receptor $\alpha 2$-subunit (platelet GPI $\alpha$ ): Homology to other integrins and the presence of a possible collagen binding domain, J. Cell Biol., 109, 397.

32. Shadle, P.J., Ginsberg, M.H., Plow, E.F. \& Barondes, S.H. (1983). Platelet-collagen adhesion: inhibition by a monoclonal antibody that binds glycoprotein IIb, J. Cell Biol., 99, 2056.

33. Besusan, H.B., Koh, T.L., Henry, K.G., Murray, B.A. \& Culp, L.A (1978). Evidence that fibronectin is the collagen receptor on platelet membranes, Proc. Natl. Acad. Sci., USA. 75, 5864.

34. Kotite, N.J. \& Cunningham, L.W. (1986). Specific adsorption of a platelet membrane glycoprotein by human insoluble collagen, J. Biol. Chem., 261, 8342.

35. Chiang, T.M. \& Jkang, A.H. (1982). Isolation and purification of collagen $\alpha-1(\mathrm{I})$ receptor from human platelet membrane, J. Biol. Chem., 257,5781 .

36. Tiffany, M.L. \& Penner, J.A. (1980). Effect of complement on collagen induced platelet aggregation, J. Lab. Clin. Med., 96, 796.

37. Holderbaum, D., Culp, L.A., Bensusan, H.B. \& Gershman, H. (1982) Platelet stimulation by antifibronectin antibodies require the $\mathrm{Fc}$ region of antibody, Proc. Natl. Acad. Sci., USA. 79, 6537.

38. Plow, E. \& Ginsberg, M.A. (1981). Specific and saturable binding of plasma fibronectin to thrombin-stimulated platelets, Blood, 56, 553

39. Tollefsen, D.M., Feagler, J.R. \& Majerus, P.W. (1974). The binding of thrombin to the surface of human platelets, J. Biol. Chem., 249, 2646

40. Jennings, L.K., Fox, J.E.B., Edwards, H.H. \& Phillips, D.R. (1981) Changes in the cytoskeletal structure of human platelets following thrombin activations, J. Biol. Chem., 256, 6927.

41. Stenberg, P.E., Shuman, M.A., Levine, S.P. \& Bainton, D.F. (1984) Redistribution of alpha-granules and their contents in thrombinstimulated platelets, J. Cell Biol., 98, 748.

42. Carlson, L., Markey, F., Blikstad, I., Persson, T. and Lindberg, U. (1979). Reorganization of actin in platelets stimulated by thrombin as measured by the DNase I inhibition assay, Proc. Natl. Acad. Sci. USA, $76,6376$.

43. Michelson, A. \& Barnard, M. (1987). Thrombin induced changes in platelet membrane glycoproteins Ib, IX and IIb-IIIa, Blood, 70, 1673.

44. Okumura, T., Hasitz, M. \& Jamieson, G.A. (1978). Platelet glycocalicin. Interaction with thrombin and role as thrombin receptor of platelet surface, J. Biol. Chem., 253, 3435

45. Takamatsu, J., Horne III, M.K. \& Gralnick, H.R. (1986). Identification of the thrombin receptor on human platelets by chemical crosslinking, J. Clin. Invest., 77, 362.

46. Phillips, D.R. \& Poh-Agen, P. (1977). Platelet membrane defects in Glanzmann's thrombasthenia: Evidence of decreased amounts of two major glycoproteins, J. Clin. Invest., 60, 535.

47. Puri, R., Zhou, F., Colman, R.F. \& Colman, R.W. (1990). Plasmin- 
induced platelet aggregation in accompanied by cleavage of aggregin and indirectly mediated by calpain, cleavage of aggregin and indirectly mediated by calpain, Am. J. Physiol., 259, 862 .

48. Marchesi, S.L. \& Chasis, J.A. (1979). Isolation of human platelet glycoproteins, Biochim. Biophys. Acta., 555, 442.

49. Fox, J.E.B. (1985). Identification of actin-binding protein as the protein linking the membrane skeleton to glycoproteins on platelet plasma membranes, J. Biol. Chem., 260, 11970.

50. Clemetson, S.L., Pfueller, S.L., Lüsher, E.F. \& Jenkins, C.S.P. (1977). Isolation of membrane glycoproteins of human blood platelets by lectin affinity chromatography, Biochim. Biophys. Acta., 464, 493.

51. Puri, R.N., Zhou, F., Bradford, H., Hu, C., Colman, R.F. \& Colman, R.W. (1989). Thrombin induced platelet aggregation involves an indirect proteolytic cleavage of aggregin by calpain, Arch. Biochem. Biophys. $271,346$.

52. Coleman, R.W., Figures, W.R., Wu, O.X., Chung, S.Y., Morinelli, T.A., Tuszynski, G.P., Colman, R.F. \& Niewiarowski, S. (1988) Distinction between glycoprotein IIla and the $100 \mathrm{kDa}$. membrane protein mediating ADP-induced platelet activation, Arch. Biochem. Biophys., 282, 298

53. Kloprogge, E. \& Akkerman, J.W.N. (1986). Platelet-activating factor (PAF-acether) induces high and low-affinity binding of fibrinogen to human platelets via independent mechanisms, Biochem. J., 240, 403.

54. Marguerie, G.A., Edington, T.S. \& Plow, E.F. (1980). Interaction of fibrinogen with its platelet receptor as part of a multistep reaction in ADP-induced platelet aggregation, J. Biol. Chem., 255, 154.

55. Mac Farlene, D.E., De Mills, D.C.B. \& Sricastava, P.C. (1982). Binding of 2 -azidoadenosine $\left[\beta-{ }^{32} \mathrm{P}\right]$-diphosphate to the receptor on intact human blood platelets which inhibits adenylate cyclase, Biochem, 21, 544 .

56. Friedhoff, L.T., Kim, E., Priddle, M. \& Sonenberg, M. (198I). The effect of altered transmembrane ion gradients on membrane potential and aggregation of human platelets in blood plasma, Biochim. Biophys. Res. Com., 102, 832

57. Di Minno, G., Thiagarajan, P., Perussia, B., Martinez, J., Shapiro, L., Trinchieri, G. \& Murphy, S. (1983). Exposure of platelet fibrinogenbinding sites by collagen, arachidonic acid, and ADP: inhibition by a monoclonal antibody to the glycoprotein IIb-Illa complex, Blood, 61 , 140.

58. Snyder, F. (1990). Platelet-activating factor and related acetylated lipids as potent biologically active cellular mediators, Am. J. Physiol., 259,697 .

59. Snyder, F. (1989). Biochemistry of platelet-activating factor: A unique class of biologically active phospholipids (42839), Proc. Soc. Exp. Biol. Med., 190, I25.

60. Marcus, A.J., Safier, L.B., Ullman, H.L., Wong, K.T.H., Broekeman, M.J., Weksler, B.B. \& Kaplan, K.L. (1981). Effects of acetyl glyceryl ether phosphorylcholine on human platelet function in vitro, Blood, 58, 1027.

61. Zimmerman, G.A., McIntyre, T.M., Mehra, M. \& Prescott, S.M. (1990), Endothelial cell-associated platelet-activating factor: A novel mechanism for signaling intercellular adhesion, J. Cell. Biol., 110, 529.

62. Billah, M.M. \& Johnson, J.M. (1983). Identification of phospholipid platelet-activating factor (1-0-alkyl-2-acetyl-sn-glycero-3phosphocholine) in human amniotic fluid and urine, Biochem. Res. Com., $113,1$.

63. Banks, J.B., Wykle, R.L.,O'Flaherty, J.T.\& Lumb, R.H.( 1988 ). Evidence for protein-catalyzed transfer of platelet activating factor by macrophage cytosol, Biochem. Biophys. Acta., 961, 48.

64. Valone, F.H. (1984). Isolateion of a platelet membrane protein which binds the platelet-activating factor 1-0-hexadecyl-2-acetyl-sn-glycero3-phosphocholine, Immunology, 52, 169

65. Nishihira, J., Ishibashi, T., Imai, Y.\& Muramatsu, T. (1985). Purification and characterization of the specific binding protein for platelet activating factor (1-0-alkyl-2-acetyl-sn-glycero-3-phosphocholine.) from human platelets, Tohoku J. Exp Med., 147, 145.

66. Hwang, S. B., Lam, M.M. \& Pongs, S. (1986). Ionic and GTP regulation of binding of platelet-activating factor to receptors and platelet-activating factor-induced activating of GTPase in rabbit platelet inembranes, J. Biol. Chem., 261, 532.

67. Rohrbach, M.S., Wheatley, C.L., Slifman, N.R. \& (Jleich, G.J. (1990). Activation of platelets by eosinophil granule protein, J. Exp. Med., 172.

68. Kornecki, E. \& Ehrlich, Y.H. (1990). Diminished responsiveness of human platelets to platelet-activating factor during pregnancy, Am. Phys. Soc. H766 - H771.

69. Landgraf, R. \& Günther, O. (1983). Vasopressin and oxytocin in cerebrospinal fluid and plasma of conscious rabbits - response to dehydration and hemorrhage, Biomed. Biochim. Acta., 42, 1339.

70. Wang, B.C., Sundet, W.A., Hakumāki, M.O.K. \& Goetz, K.L. (1987) Vasopressin and renin responses to hemorrhage in conscious, cardiacdenervated dogs, Am. J. Physiol., 245, H399.

71. Vittet, D., Randot, A., Cantau, B., Launay, J-M. \& Chevillard, C. (1986). Nature and properties of human platelet vasopressin receptors, Biochem. J., 233, 631.

72. Siess, W., Lorenz, R., Roth, P. \& Weber, P.C. (1982). Plasma catecholamines, platelet aggregation and associated thromboxane formation after physical exercise, smoking or norepinephrine infusion, Circulation, 66, 44

73. Hollister, A.S., Onrot, J., Lance, S., Nadeau, J.H.J. \& Robertson, D. (1986). Plasma catecholamine modulation of alpha, adrenoreceptor agonist affinity and sensitivity in normotensive and hypertensive human platelets, J. Clin. Invest., 77, 1416.

74. Alexander, R.W., Cooper. B. \& Handin, R.l. (1978). Characterization of the human platelet $\alpha$-adrenergic receptor. Correlation of $\lceil$ 'H|dihydroergocryptine hinding with aggregation and adenylate cyclase inhibition, J. Clin. Invest., 61, 1136.

75. Regan, J.W., Nakata, H., Demarinis, R.M., Caron, M.G. \& Lefkowitz, R.J. (1986). Purification and characterization of human platelet $\alpha_{2}$ adrenergic receptor, J. Biol. Chem., 261, 3894.

76. Mac Farlane, D.E. \& Mills, D.C.B. (1975). The effect of ATP on platelets; evidence against the central role of released ADP in primary aggregation, Blood, 46, 309.

77. Jacobs, K.H., Saur, W. \& Schultz, G. (1978). Inhibition of platelet adenylate cyclase by epinephrine requires GPT, Febs. Lett., 85, 167.

78. Weiss, H.J. \& Rogers, J. (1971). Fibrinogen and platelets in the primary arrest of bleeding. Studies in two patients with congenital afibrinogenemia, N. Engl. J. Med., 285, 369.

79. Marguerie, G.A., Thomas-Maison, N., Larrieu, M-J, \& Plow, E.F. (1982). The interaction of fibrinogen with human platelets in a plasma milieu, Blood, 59, 91.

80. Marguerie, G.A., Plow, E.F.\& Edgington, T.S. (1979). Human platelets posses an inducible and saturatable receptor specific for fibrinogen, $J$. Biol. Chem., 254, 5357.

81. Peerschke, E.I.D.\& Zucker, M.B. (1981). Fibrinogen receptor exposure and aggregation of human blood platelets produced by ADP and chilling, Blood, 57, 663 .

82. Van Marwijk Kooy, M., Borghuis, L., Van Prooijn, H.C., AartsRiemens, M.I. \& Akkerman, J.W.N. (1990). Irradiation of platelets with UV-B light exposes fibrinogen binding sites via an intracellular mechanism, Brit. J. Haemat., 76, 531

83. Parise, L.V. \& Phillips, D.R. (1985). Reconstitution of the purified platelet fibrinogen receptor, J. Biol. Chem., 260, 10698.

84. Gardner, J.M. \& Hynes, R.O. (1985). Interaction of fibronectin with receptors on platelets, Cell, $42,439$.

85. Fujimoto, T. \& Hawiger, J. (1982). Adenosine diphosphate induces binding of von Willebrand factor to human platelets, Nature, 154.

86. Kloczewiak, M., Timmons, S. and Hawiger, J. (1982). Localization of a site interacting with human platelet receptor on carboxy-terminal segment of human fibrinogen gamma chain, Biochem. Biophys. Res. Com., 107, 181 .

87. Tranqui, L., Andrieux, A., Hudry-Clergean, G., Ryckewaert, J-J., Soyez, S., Chapel, A., Ginsberg, M.H., Plow, E.F. \& Marguerie, G (1989). Differential structural requirements for fibrinogen binding to platelets and to endothelial cells, J. Cell Biol., 108, 2519. 